\title{
Inflexibility Processes as Predictors of Social Functioning in Chronic Psychosis
}

Tatiana Arboleya ${ }^{\mathrm{a}}$, Ana González-Menéndez ${ }^{\mathrm{b} *}$, Helena Ordoñez ${ }^{\mathrm{b}}$, David G. Pando ${ }^{\mathrm{a}}$ and Mercedes Paíno ${ }^{\mathrm{b}}$.

${ }^{a}$ ISPA- Health Research Institute of the Principality of Asturias, Oviedo, Spain; ${ }^{\mathrm{b}}$ Department of Psychology. University of Oviedo, Oviedo, Spain

*Corresponding author. Email: anagon@uniovi.es

\begin{abstract}
Within the context of a transdiagnostic perspective, the Psychological Inflexibility (PI) construct refers to rigid attempts to control undesirable private events at the expense of value-guided actions. Given the framework of PI as a construct associated with poor recovery and social functioning in people with psychosis, the main objective was to explore the role of two processes related to inflexibility (experiential avoidance, -EA-, and self-concealment) in predicting social functioning. The study sample of 103 patients with chronic psychosis was administered the Acceptance and Action Questionnaire-II, the Self Concealment Scale, and the Social Functioning Scale as the main measures. The differential weight of insight and clinical impression, also associated with social functioning, was analyzed by regression analysis. The results showed that private experiences led to rigid patterns of PI in people with psychosis and that the process that best predicted social functioning in these patients was EA, which explained $21.6 \%$ of the variance. EA, chronicity and global clinical impression together explained $35.2 \%$ of the variance. These results contribute to progress in understanding the role of PI in psychosis, as well as associated factors. The use of strategies facilitating acceptance, and not elimination of psychotic experiences, may be a possible strategy for addressing the impaired daily functioning of these patients.
\end{abstract}

Keywords: psychological inflexibility; psychosis; social functioning; self-concealment. 


\section{Introduction}

Psychosis is often related to poor functioning, including occupational and social functioning, unemployment and living alone (Burns \& Patrick, 2007; Echarri-Santesteban et al., 2017; Gorwood et al., 2013). When psychosis becomes chronic, deficits in social functioning remain prominent and increase the risk of social exclusion, poverty and loneliness. These personal and social consequences impede recovery, especially as understood in terms of life goals and acceptance, with or without symptoms, of the fact of living with psychosis (Andresen, Oades \& Caputi, 2003; Bradstreet \& Connor, 2005)

The psychological inflexibility construct (PI) is not supportive of this concept of recovery. PI refers to rigid attempts to control or change undesirable private events (e.g., thoughts, affect, bodily sensations) at the expense of value-guided actions (Bond et al., 2011). PI was introduced within the context of Acceptance and Commitment Therapy (ACT; Hayes, Strosahl \& Wilson, 2012), a third wave CBT therapy which emphasizes an indefensible relationship with the symptoms and encourages pursuance of a life concentrated on personal values. The contrary is the acceptance of private experiences and psychological flexibility. The psychological flexibility model focuses on changing how people relate to distressing internal experiences and on engaging in value-based actions, regardless of such experiences (Levin at al., 2014). PI has demonstrated evidence of its utility as a transdiagnostic dimension of a broad range of psychological disorders (Ruiz, 2010).

The observation that PI is a construct linked to substandard recovery and to poor functioning in people diagnosed with schizophrenia has also served as justification for study of the use of ACT in this population (Varese, Tai, Pearson, \& Mansell, 2016). Several studies have reported that many patients with psychosis (especially those who hear voices and have delusional beliefs related to guilt, humiliation and shame) show many avoidance and inflexibility patterns and little acceptance behavior (Morrison, Haddock, \& Tarrier, 1995). At 
the same time, robust relationships have been found between quality of life reported by psychotic patients and ways of regulating behavior based on acceptance (Vilardaga, Hayes, Atkins, Breese, \& Kambiz, 2013). Cramer, Lauche, Haller, Langhorst, \& Dobos (2016) concluded that recent reviews in the field of psychosis have found that ACT was associated with shorter hospitalization periods, lower hospitalization rates and fewer positive symptoms in patients treated.

Another variable which is related with the PI model is self-concealment (SC). Larson and Chastain (1990, p.440) define it as the tendency to hide distressing and potentially embarrassing personal information. Although these authors originally suggested that more traumatic experiences are concealed more often, recent studies link SC to personal inadequacy, rumination and worry (Wismeijer, 2011). Conceptually, while considered an adaptive behavioral tendency in some sociocultural contexts (Wallace \& Constantine, 2005), SC may serve as a maladaptive control and avoidance-focused emotion/behavior regulation strategy in other contexts (Masuda et al., 2011). In a review, Larson, Chastain, Hoyt, \& Ayzenberg (2015) found positive correlations between levels of SC and PI, suggesting that SC functions as a mediator of PI. SC is probably detrimental when it is linked to general maladaptive emotion and behavior regulation. This finding is not surprising as both constructs reflect intentional rigid efforts to avoid and downregulate unwanted internal experiences (Masuda et al., 2017). Recent findings support the notion that PI is a key underlying process that establishes the link between self-concealment and a range of psychopathology variables (Larson et al., 2015; Masuda et al., 2017).

In just a few years, $\mathrm{SC}$ has become a fruitful line of research in the framework of eating disorders, especially anorexia (Vandereycken \& Van Humbeeck, 2008). It has also been related to severity of depression (Friedlander, Nazem, Fiske, Nadorff, \& Smith, 2012) and anxiety (Edmonds, Masuda, \& Tully, 2014; Wheaton, Sternberg, McFarlane, \& Sarda, 
2016), as well as suicidal behavior (Friedlander et al., 2012), with maladaptive perfectionism (Kawamura \& Frost, 2004) and with stigma in mental health (Mendoza, Masuda \& Swartout, 2015). However, this variable has never been studied in psychosis.

Some of the literature suggests that PI underlies different forms of psychopathology, including psychosis, and can be manifested in different topographies including SC (Edmons, Masuda \& Tully, 2014). Although there is no past research on the effects of SC on social functioning in people with psychotic experiences, there is an increasing amount of research identifying this maladaptive pattern of deliberately keeping personal information from others in a range of psychological problems. The aim of this study was to explore the role of EA and self-concealment in predicting social functioning in patients with chronic psychosis.

Furthermore, and since factors such as insight, severity and chronicity of psychosis have been linked to worse social functioning, this study attempted to analyze the differential weight of each of these variables in social functioning.

\section{Method}

\section{Participants and study procedure}

The study was carried out with a convenience sample of outpatients from a Mental Health Public Service in Asturias, a province in northern Spain. Demographic and clinical features of the sample are presented in Tables 1 and 2. Participants who showed signs of severe physical illness, episode of acute psychosis, intellectual disability and/or primary diagnosis of substance dependence were excluded. 103 of 286 outpatients volunteered to participate in the study after signing an informed consent form. All of them met ICD-10 criteria (WHO, 1992) for the diagnostic categories included in Table 2. The sample had been developing the disorder over many years ( $M=19$ years; SD: 10.88), and 70\% had some degree of recognized employment disability. Two thirds of the participants had never been married (63.1\%) and 
most were living with their families of origin (56.3\%). All participants were receiving psychopharmacological treatment at the time of the study. The mean age of the entire group was 49.63 years $(\mathrm{SD}=12.28)$.

[Table 1 about here]

From July 2017 to September 2018, participants were evaluated by the psychiatrist responsible for them (ICG-ESQ y SUMD) and by a mental health nurse (SFS, AAQ-II y SCS) with over ten years of clinical experience. All procedures were approved by the local ethics committee. Participant flow is outlined in Fig. 1.

[Figure 1 about here]

\section{Measures}

The Acceptance and Action Questionnaire - II (AAQ-II; Bond et al., 2011) was used to assess unwillingness to experience undesirable thoughts and feelings and interference of these internal events in daily functioning. AAQ-II is a 7-item questionnaire where respondent rate the degree to which each statement applies to them, from 1 (never true) to 7 (always true). The total score is derived from the sum of responses to all items, with greater values indicating greater psychological inflexibility. Lower scores suggest greater acceptance of mental experiences and persistence with life goals in the face of these experiences. The scale shows good internal consistency $(\alpha=$.88) (Ruiz, Langer, Luciano, Cangas, \& Beltrán, 2013).

The Self Concealment Scale (SCS; Larson \& Chastain, 1990) is a self-report inventory designed to measure a person's tendency to conceal personal information that is distressing (e.g., There are lots of things about me that I keep to myself). The SCS includes 10 items and employs a 5- point Likert scale ranging from 1 (strongly disagree) to 5 (strongly agree) for each item. The total score is derived from the sum of responses to all items, with greater values indicating greater self-concealment. The SCS has adequate psychometric properties, 
with an inter-item reliability estimates of .81 (Masuda, Anderson, Wendell, Price, Feinstein \& Chou, 2011).

The Social Functioning Scale (SFS; Birchwood, Smith, Cochrane, Wetton \& Copestake, 1990) was used to evaluate the seven dimensions of functioning: (1) social engagement/withdrawal, (2) interpersonal; (3) pro-social activities; (4) recreational activities (5) independence-competence (6) independence-performance; and (7) employment/occupation. The SFS is a reliable, valid and sensitive measure of social functioning relevant to the impairments and needs of individuals with schizophrenia, useful to researchers (Birchwood et al., 1990).

The Clinical Global Impression-Schizophrenia Scale (CGI-SCH; Haro et al. (2003) was administered to evaluate positive, negative, cognitive and depressive symptoms and overall severity in schizophrenia. The CGI-SCH has two categories: severity of illness and degree of change. Severity of illness evaluates the clinical situation during the week previous to the assessment, while the degree of change evaluates the change in disorder severity between two points in time. In this study, only disorder severity was used. A seven-point ordinal scale is applied to evaluate these categories. The CGI-SCH scale is a valid, reliable instrument for evaluating severity and treatment response in schizophrenia.

The Scale to Assess Unawareness in Mental Disorders (SUMD; Amador, Strauss, Yale, Flaunm \& Endicott, 1993) was used to assess global awareness of having a mental disorder, awareness of the effects of medication and awareness of the social consequences of having a mental disorder. All scores range from 1 to 5, with higher scores indicating poorer awareness or attribution. Reliability and external validity of the Spanish adaptation of the SUMD scale is similar to the original version.

\section{Data analysis}


First, a descriptive analysis was done of all the sociodemographic and clinical variables. The qualitative variables were expressed as a frequency distribution and the quantitative variables as the arithmetic mean and standard deviation.

Then the association between clinical variables was analyzed by calculating the Pearson's correlation coefficient.

Finally, we wanted to find out whether the insight variables (SUMD), global clinical awareness (CGI-SCH), experiential avoidance (AAQ-II), self-concealment (SCS) and chronicity could be adequate predictors of global social functioning (SFS), and if so, how much. A linear regression analysis was performed for this.

IBM SPSS Statistics (V.25.0) was used for data analysis.

\section{Results}

\section{Sample characteristics}

Over $60 \%$ of the participants were diagnosed with Paranoid Schizophrenia according to ICD10 criteria (WHO, 1992), followed by Delusional Disorder (13\% of the participants). More than half were taking or had habitually taken some type of toxic substance during their lifetime. The psychotic symptoms began at around 30 years of age, although the range was quite wide and spanned ages from 9 to 65 . The participants had been in pharmacological treatment for about 17 years (oral, depot or both), and had been hospitalized more than twice.

[Table 2 about here]

The sample could be said to have medium-to-low overall social functioning. The mean scores on both the AAQ-II (M=26.12; SD: 11.23) and SCS (M=32; SD: 12.96) were high, especially on the SCS scale. 
None of the participants scored the maximum of 7 points on the Global Clinical Impression Scale. The mean of 4.20 (SD: 1.05) shows that patients were evaluated by their psychiatrists as moderately to very severe.

The three insight subscales (SUMD) showed a very similar mean of 2.70 to 2.80 . Therefore, these participants would have an intermediate insight with respect to their own disorder, to the social consequences and the effects of medication.

Table 2 shows the descriptive data for the study clinical variables.

\section{Correlational and Regression Analysis}

Significant correlations were found between social functioning and the rest of variables, with strong correlations between social functioning and PI $(\mathrm{r}=-.465, \mathrm{p} \leq .000)$, and between social functioning and $\mathrm{SC}(\mathrm{r}=-.428, \mathrm{p} \leq .000)$. Significant correlations were not found between chronicity and PI or SC, or between insight and PI or SC. Table 3 shows the correlation matrix.

[Table 3 about here]

Finally, and after testing for the necessary statistical assumptions, a linear regression analysis was performed to fit a model that enabled the isolated and combined contributions of the PI variables (EA and self-concealment) to overall social functioning of the participants.

The results showed that the variables entered in the regression equation explaining social functioning were EA, chronicity and global clinical impression. EA explained $21.6 \%$ of the differences in the criterion, EA and chronicity explained $33.3 \%$ and with the full model, the proportion of estimated variance was $35.2 \%$.

[Table 4 about here] 


\section{Discussion}

This study was carried out with the objective of analyzing the presence and weight of certain PI processes on the social functioning of persons with chronic psychosis. In general, the results suggest that EA, one of the main processes explaining PI, is related to social functioning of people with chronic psychosis.

The scores on experiential avoidance evaluated using the AAQ-II show that the participants showed rigid patterns in their relationship with their private experiences. In our study we observed a mean score slightly higher than reported by Morris, Garety, \& Peters (2014) with a similar sample to the one in this study.

Previous literature has documented both active avoidance and suppression as coping strategies usually used by psychotic patients (Kimhy et al., 2012; Livingstone, Harper, \& Gillanders, 2009; Moritz, Lüdtke Westermann Hermeneit Watroba, \& Lincoln, 2016; van der Meer, van't Wout, \& Aleman, 2009). This study was able to confirm that evidence. The strong relationship observed between EA and SC shows that it is the avoiders who tend to hide negatively evaluated personal information the most. Everything suggests that the participants were struggling against their unwanted psychological contents (thoughts, voices, feelings, emotions), which counterintuively led them to the persistent presence of more of those undesirable contents, thus establishing a circular maladaptive regulation. This intolerance toward private contents, characteristic of the process called PI (Hayes, Luoma, Bond, Masuda \& Lillis, 2006), has been observed in samples of patients with psychological heterogeneity problems (e.g., Litwin, Goldbacher, Cardaciotto \& Gambrel, 2017, in eating disorders; Brem, Shorey, Anderson \& Stuart, 2017, in compulsive sex behavior; and Wagener, Baeyens \& Blairy, 2016, in depression). All of this evidence has demonstrated the 
usefulness of the PI construct as a transdiagnostic variable of mental symptomatology (Levin et al., 2014).

The correlational study confirmed that PI patterns based on EA and SC negatively affect social functioning of the participants. It seems that people with schizophrenia who tend to isolation, who have fewer leisure activities, and who are less involved in productive employment or in structured programs of daily activity are those who show the most rigid and inflexible behavior. These results are in line with previous research which shows clear associations in psychotic patients between forms of avoidance-based behavior regulation and lower quality of life (e.g. Vilardaga, et al., 2013), and also with others which have found in patients with chronic psychosis, an increase in social and personal functioning by increasing acceptance and commitment-based regulation (Salgado, Luciano \& Gutiérrez, 2013). In our study, the inflexibility observed in patients with poor social functioning suggests a struggle with symptoms which impedes participants from becoming the managers of their own lives, which in the long run invade and disrupt all the facets that generally define it (work, intimate relations, family relations, etc.). Furthermore, patients who in the opinion of the psychiatrists assigned to them have the highest scores in severity of psychosis (evaluated by the CGI), not only have worse social functioning and employment, but are also those show the most rigid experiential avoidance and self-concealment patterns.

We might wonder to what extent social functioning of the patients in the sample is determined by acceptance/avoidance of their private experiences. In this sense, the results of the predictive analysis are revealing. EA alone explained nearly $22 \%$ of the variance in overall social functioning. However, in spite of having a high correlation with the criterion, the $\mathrm{SC}$ variable did not enter in the regression equation. This shows that experiential avoidance and self-concealment are very closely related to each other, and that the correlation of SC with social functioning must be due mostly to what it has in common with EA. 
Although showing lower correlations than self-concealment, other variables that were predictors of subjects' functioning were duration of the disorder in years and psychosis severity score as evaluated by the CGI. In this case, the proportion of explained variance increased to $35.2 \%$.

The duration of participant psychosis was a mean of over 19 years. The predictive capacity of this variable is not surprising, especially considering that psychosis normally begins at an early age, and that the diagnosis of schizophrenia alone has consequences that prescribe more than proscribe poor social functioning (Angermeyer, Holzinger, Carta, \& Schomerus, 2011). In view of the above, we believe that chronicity per se is not the most relevant explanatory variable. Probably it is stigma/self-stigma associated with "mental illness", the obligatory medication and its effects, and the diagnostic label itself which are a threat to developing a normal life, contributing to gradual decline in their capacity for adapting to school and employment, in psychosocial performance, and generally affecting the quality of life of the persons diagnosed (López-Santiago, Blas \& Gómez, 2012). As confirmed by Masuda et al. (2009), PI is an important process involved in the development and maintenance of stigmatization.

It is also worth mentioning the results found in evaluating insight. In samples with a diagnosis of schizophrenia, poor insight has consistently been associated with worse social adjustment, poor functioning and worse therapeutic compliance (Barret et al., 2010; Valiente, Provencio, Espinosa, Duque \& Everts, 2015). Some of these relationships were confirmed by our study, although not in the case of EA. None of the facets of insight evaluated by the SUMD scale (awareness of disorder, effects of medication, social consequences of the disorder) were related with PI. Neither did insight enter in the regression equation as an explanatory factor of psychosocial functioning, which suggests poor awareness of the disorder does not imply worse social, relational or employment adjustment, also contradicting previous 
research (e.g., Erol, Delibas, Bora \& Mete, 2014; Kurtz, Olfson, \& Rose, 2013) where these relationships do appear. The result observed here is in line with other studies which show that appropriate insight may not be advantageous in all circumstances, and leads to worse results in anxiety, depression, satisfaction with life and suicidal behavior (Cavelti, Kvrgic, Beck, Rüsch, \& Vauth, 2012; Or et al., 2013; Rathod, Kingdon, Smith, \& Turkington, 2005). This phenomenon, known as the paradox of insight (Chio, Mak, Chan, \& Tong, 2018; Lysaker, Pattison, Leonhardt, Phelps, \& Vohs, 2018), poses clinicians the dilemma of whether to promote this form of insight in patients or not.

In fact, the evaluation of insight in this study reports exclusively on medical insight, illness, symptoms and medication, which is stigmatizing (Bouvet \& Bouchoux, 2015) and obligates acceptance of biomedical explanations of psychotic experiences. Although the study of unawareness of the disorder in psychosis is a legitimate objective of research, the promotion of narrative insight more than clinical would enable the personal sense, not necessarily medical, of the symptoms to be explored (Johnson, Sathiyaseelan, Charles, Jeyaseelan, \& Jacob, 2012), and also offer an appropriate alternative facilitating learning acceptance, not elimination, of psychotic experiences.

In brief, the evidence presented here joins what has been found in previous studies documenting the transdiagnostic role of PI in the onset, maintenance and evolution of many mental disorders, including psychosis (Goldstone, Farhall \& Ong, 2011; Bacon, Farhall \& Fossey, 2014; Morris, Garety, \& Peters, 2014; Vilardaga et al., 2013; Udachina, Varese, Myin-Germeys, \& Bentall, 2014; Varese et al., 2016). According to these results, PI can explain the poor social functioning associated with these disorders. People with psychosis define recovery in terms of reconstructing their own lives and recovering their sense of self (Pitt, Kilbride, Nothard, Welford \& Morrison, 2007). We think that the use of therapies emphasizing acceptance of psychotic experiences, authentic support of the patient avoiding 
value judgments, as well as empathetic understanding of the symptoms in the context of their own experience can improve the desired results in social functioning. The goal of ACT is that transdiagnostic focus. The processes analyzed in the therapy and which account for psychological flexibility make ACT a treatment anchored in recovery. ACT promotes compassion for oneself and social connection by changing the focus of the clients, who advance from control of symptoms to connection with what is important to them. It also encourages active participation in life, as something the clients desire, that they observe in others and may have had in the past. The focus of ACT also helps find personal significance, as it teaches them to dignify the inescapable sorrow and suffering by living as part of the process of doing the things they really value.

The present findings are not without limitations. The cross-sectional nature of the study prevents any causal inferences. Future studies should analyze the moderating role of experiential avoidance on self-stigma and biomedical insight evaluated here. In addition, since self-concealment as evaluated by the SCS scale seems to be well represented by experiential avoidance, it would not be necessary to add its evaluation in samples of patients with psychosis.

\section{Disclosure of interest}

The authors report no conflict of interest.

\section{Funding}

Ministry of Economy and Competitiveness (MINECO) (Reference PSI2016-79524-R).

ORCID: Ana González-Menéndez. https://orcid.org/0000-0002-1164-8617 


\section{References}

Amador, X.F., Strauss, D.H., Yale, S.A., Flaum, M.M., Endicott, J., \& Gorman, J.M. (1993). Assessment of insight in psychosis. American Journal of Psychiatry, 150(6), 873-879.

Angermeyer, M.C., Holzinger, A., Carta, M.G. \& Schomerus, G. (2011). Biogenetic explanations and public acceptance of mental illness: systematic review of population studies. The British Journal of Psychiatry, 199(5), 367-372.

Andresen, R., Oades, L. \& Caputi, P. (2003). The experience of recovery from schizophrenia: Towards an empirically validated stage model. Australian and New Zealand Journal of Psychiatry, 37, 586-594. doi:10.1046/j.1440-1614.2003.01234.x.

Goldstone, E., Farhall, J. \& Ong, B (2011). Life hassles, experiential avoidance and distressing delusional experiences. Behaviour Research and Therapy, 4 (4), 260-266.

Bacon, T., Farhall, J. \& Fossey, E. (2014). The active therapeutic processes of Acceptance and Commitment Therapy for persistent symptoms of psychosis: clients' perspectives. Behavioural and Cognitive Psychotherapy, 42(4), 402-420.

Barrett, E.A., Sundet, K., Faerden, A., Agartz, I., Bratlien, U., Romm, K.L., Mork, E., Rossberg, J.L., Steen, N.E., Andreassen, O.A. \& Melle, I. (2010). Suicidality in first episode psychosis is associated with insight and negative beliefs about psychosis. Schizophrenia Research, 123(2-3), 257-262.

Birchwood, M., Smith, J., Cochrane, R., Wetton, S.C.S \& Copestake, S.O. (1990). The Social Functioning Scale. The development and validation of a new scale of social adjustment for use in family intervention programmes with schizophrenic patients. The British Journal of Psychiatry, 157(6), 853-859. 
Bond, F.W., Hayes, S.C., Baer, R.A., Carpenter, K.M., Orcutt, H.K., Waltz, T., et al. (2011). Preliminary psychometric properties of the Acceptance and Action Questionnaire-II: A revised measure of psychological inflexibility and experiential avoidance. Behavior Therapy, 42, 676-688.

Bouvet, C. \& Bouchoux, A. (2015). Exploring the relationship between internalized stigma, insight and depression for inpatients with schizophrenia. L'Encephale, 41(5), 435-443.

Bradstreet, S., \& Connor, A. (2005). Communities of recovery. Mental Health Today.

In. Bonney, S. \& Stickley, T. (2008). Recovery and mental health: a review of the British literature. Journal of Psychiatric and Mental Health Nursing, 15 (2), 140-153.

Brem, M.J., Shorey, R.C., Anderson, S., \& Stuart, G.L. (2017). Depression, anxiety, and compulsive sexual behaviour among men in residential treatment for substance use disorders: The role of experiential avoidance. Clinical Psychology \& Psychotherapy, $39,264-278$

Burns, T., Patrick, D. (2007). Social functioning as an outcome measure in schizophrenia studies. Acta Psychiatrica Scandinavica, 116, 6, 403-418.

Cavelti, M., Kvrgic, S., Beck, E.M., Rüsch, N. \& Vauth, R. (2012). Self-stigma and its relationship with insight, demoralization and clinical outcome among people with schizophrenia spectrum disorders. Comprehensive Psychiatry, 53(5), 468-479.

Chio, F.H.N., Mak, W.W.S., Chan, R.C.H. \& Tong, A.C.Y. (2018). Unraveling the insight paradox: One-year longitudinal study on the relationships between insight, self-stigma and life satisfaction among people with schizophrenia spectrum disorders. Schizophrenia Research, 197, 124-130. 
Cramer, H., Lauche, R., Haller, H., Langhorst, J. \& Dobos, G. (2016). Mindfulness-and Acceptance-based interventions for psychosis: A systematic review and meta-analysis. Global Advances in Health and Medicine, 5(1), 30-43.

Echarri-Santesteban, O., Paino, M., Rice, S., González-Blanch, C., McGorry, P., Gleeson, J., \& Álvarez-Jiménez, M. (2017). Predictors of functional recovery in first-episode psychosis: A systematic review and meta-analysis of longitudinal studies. Clinical Psychology Review, 58, 59-75.

Edmonds, J., Masuda, A., \& Tully, E. (2014). Relations among self-concealment, mindfulness and internalizing problems. Mindfulness, 5, 497-504.

Erol, A., Delibas, H., Bora, O., \& Mete, L. (2014) The impact of insight on social functioning in patients with schizophrenia. International Journal of Social Psychiatry, 61(4), 379385.

Friedlander, A., Nazem, S., Fiske, A., Nadorff, M.R., \& Smith, M.D. (2012). Selfconcealment and suicidal behaviors. Suicide \& Life-Threatening Behavior, 42(3), 332340.

Gorwood, P., Burns, T., Juckel, G., Rossi, A., San, L., Hargarter, L. \& Schreiner, A. (2013). Psychiatrists' perceptions of the clinical importance, assessment and management of patient functioning in schizophrenia in Europe, the Middle East and Africa. Annals of General Psychiatry, 12, 8, 1-8.

Haro, J.M, Kamath, S.A., Ochoa, S., Novick, D., Rele, K., Fargas, A., ...Jones, P.B. (2003). The Clinical Global Impression-Schizophrenia scale: A simple instrument to measure the diversity of symptoms present in schizophrenia. Acta Psychiatrica Scandinavica, 107(416), 16-23. 
Hayes, S.C., Luoma, J.B., Bond, F.W., Masuda, A. \& Lillis, J. (2006). Acceptance and Commitment Therapy: model, processes and outcomes. Behaviour Research and Therapy, 44(1), 1-25.

Hayes, S. C., Strosahl K. D. \& Wilson, K. G. (2012). Acceptance and commitment therapy: The process and practice of mindful change. New York: Guilford.

Johns, L.C., Oliver, J.E., Khondoker, M., Byrne, M., Jolley, S., Wykes, T. \& Morris, E.M. (2016). The feasibility and acceptability of a brief Acceptance and Commitment Therapy (ACT) group intervention for people with psychosis: The 'ACT for life' study. Journal of Behavior Therapy and Experimental Psychiatry, 50, 257-263.

Johnson, S., Sathiyaseelan, M., Charles, H., Jeyaseelan, V. \& Jacob, K.S. (2012). Insight, psychopathology, explanatory models and outcome of schizophrenia in India: a prospective 5-year cohort study. BMC Psychiatry 12(1), 159.

Kawamura, K.Y. \& Frost, R.O. (2004). Self-Concealment as a mediator in the relationship between perfectionism and psychological distress. Cognitive Therapy and Research, 28(2), 183-191.

Kimhy, D., Vakhrusheva, J., Jobson-Ahmed, L., Tarrier, N., Malaspina, D. \& Gross, J.J. (2012). Emotion awareness and regulation in individuals with schizophrenia: Implications for social functioning. Psychiatry Research, 200(2-3), 193-201.

Kurtz, M.M., Olfson, R. \& Rose, J. (2013). Self-efficacy and functional status in schizophrenia: Relationship to insight, cognition and negative symptoms. Schizophrenia Research, 145(1-3), 69-74. 
Larson, D.G. \& Chastain, R.L. (1990). SC: Conceptualization, measurement and health implications. Journal of Social and Clinical Psychology, 9, 439-455.

Larson, D.G., Chastain, R.L., Hoyt, W.T. \& Ayzenberg, R. (2015). Self-concealment: integrative review and working model. Journal of Social and Clinical Psychology, 34(8), $705-774$.

Levin, M.E., MacLane, C., Daflos, S., Pistorello, J., Hayes, S.C., Seeley, J. \& Biglan, A. (2014). Examining psychological inflexibility as a transdiagnostic process across psychological disorders. Journal of Contextual Behavioral Science, 3, 155-163.

Litwin, R., Goldbacher, E.M., Cardaciotto, L. \& Gambrel, L.E. (2017). Negative emotions and emotional eating: The mediating role of experiential avoidance. Eating and Weight Disorders, 22(1), 97-104.

Livingstone, K., Harper, S. \& Gillanders, D. (2009). An exploration of emotion regulation in psychosis. Clinical Psychology \& Psychotherapy, 16(5), 418-430.

López-Santiago, J., Blas, L.V. \& Gómez, M. (2012). Efectividad de un programa de tratamiento asertivo comunitario para pacientes con trastorno mental grave. Revista de Psicopatología y Psicología Clínica, 17, 1-10.

Lysaker, P.H., Pattison, M.L., Leonhardt, B.L., Phelps, S. \& Vohs, J.L. (2018). Insight in schizophrenia spectrum disorders: relationship with behavior, mood and perceived quality of life, underlying causes and emerging treatments. World Psychiatry, 17(1), 1223. 
Masuda, A., Hayes, S.C., Lillis, J. et al. (2009). The relation between psychological flexibility and mental health stigma in acceptance and commitment therapy: a preliminary process investigation. Behavior and Social Issues, 18, 25-40

Masuda, A., Anderson, P.L., Wendell, J.W., Price, M., Feinstein, A.B. \& Chou, Y.Y. (2011). Psychological flexibility mediates the relations between self-concealment and negative psychological outcomes. Personality and Individual Differences, 50(2), 243-247.

Masuda, A., Tully, E., Drake, C., Tarantino, N., Ames, A., \& Larson, D. (2017).Examining self-concealment within the framework of psychological inflexibility and mindfulness: A preliminary cross-sectional investigation. Current Psychology, 36 (1), 184-191.

Mendoza, H., Masuda, A. \& Swartout, K.M. (2015). Mental health stigma and selfconcealment as predictors of help-seeking attitudes among latina/o students in the United States. International Journal for the Advancement of Counselling, 37(3), 207222.

Moritz, S., Lüdtke, T., Westermann, S., Hermeneit, J., Watroba, J. \& Lincoln, T.M. (2016). Dysfunctional coping with stress in psychosis. An investigation with the Maladaptive and Adaptive Coping Styles (MAX) questionnaire. Schizophrenia Research, 175(1-3), 129-135.

Morris, E.M., Garety, P. \& Peters, E. (2014). Psychological flexibility and nonjudgemental acceptance in voice hearers: relationships with omnipotence and distress. Australian and New Zealand Journal of Psychiatry, 48(12), 1150-1162.

Morrison, A.P., Haddock, G. \& Tarrier, N. (1995). Intrusive thoughts and auditory hallucinations: A cognitive approach. Behavioural and Cognitive Psychotherapy, 23, 265-280. 
Or, S.E.B., Hasson-Ohayon, I., Feingold, D., Vahab, K., Amiaz, R., Weiser, M. \& Lysaker, P.H. (2013). Meaning in life, insight and self-stigma among people with severe mental illness. Comprehensive Psychiatry, 54(2), 195-200.

Pitt, L., Kilbride, M., Nothard, S., Welford, M. \& Morrison, A.P. (2007). Researching recovery from psychosis: a user-led project. Psychiatric Bulletin, 31(2), 55-60.

Rathod, S., Kingdon, D., Smith, P. \& Turkington, D. (2005). Insight into schizophrenia: The effects of cognitive behavioural therapy on the components of insight and association with sociodemographics: data on a previously published randomized controlled trial. Schizophrenia Research, 74(2-3), 211-219.

Ruiz, F.J. (2010). A review of Acceptance and Commitment Therapy (ACT) empirical evidence: correlational, experimental, psychopathology, component and outcome studies. International Journal of Psychology and Psychological Therapy, 10(1), 125162.

Ruiz, F.J., Langer, A.I., Luciano, C., Cangas, A.J. \& Beltrán, I. (2013). Measuring experiential avoidance and psychological inflexibility: The Spanish version of the Acceptance and Action Questionnaire-II. Psicothema, 25(1), 123-129.

Salgado, C.F., Luciano, C., \& Gutiérrez, O. (2013). Eficacia de la Terapia de Aceptación y Compromiso en personas con Trastorno Mental Crónico. Un ensayo aleatorizado. Informaciones Psiquiátricas, 214(4), 385-401.

Torres, A. \& Olivares, J.M. (2005) Validation of the Spanish version of the Social Functioning Scale. Actas Españolas de Psiquiatría, 33(4), 216-220. 
Udachina, A., Varese, F., Myin-Germeys, I. \& Bentall, R.P. (2014). The role of experiential avoidance in paranoid delusions: An experience sampling study. The British Journal of Clinical Psychology, 53(4), 422-432.

Valiente, C., Provencio, M., Espinosa, R., Duque, A. \& Everts, F. (2015). Insight in paranoia: The role of experiential avoidance and internalized stigma. Schizophrenia Research, 164(1-3), 214-220.

Vandereycken, W. \& Van Humbeeck, I. (2008). Denial and concealment of eating disorders: A retrospective survey. European Eating Disorders Review, 16(2), 109-114.

Van der Meer, L., van’t Wout, M. \& Aleman, A. (2009). Emotion regulation strategies in patients with schizophrenia. Psychiatry Research, 170(2-3), 108-113.

Varese, F., Tai, S.J., Pearson, L. \& Mansell, W. (2016). Thematic associations between personal goals and clinical and non-clinical voices (auditory verbal hallucinations). Psychosis, 8(1), 12-22.

Vilardaga, R., Hayes, S.C., Atkins, D.C., Bresee, C. \& Kambiz, A. (2013). Comparing experiential acceptance and cognitive reappraisal as predictors of functional outcome in individuals with serious mental illness. Behaviour Research and Therapy, 51, 425-433.

Wallace, B. C., \& Constantine, M. G. (2005). Africentric cultural values, psychological helpseeking attitudes, and self-concealment in African American college students. Journal of Black Psychology, 31(4), 369-385.

Wagener, A., Baeyens, C. \& Blairy, S. (2016). Depressive symptomatology and the influence of the behavioral avoidance and activation: A gender-specific investigation. Journal of Affective Disorders, 193, 123-129. 
Wheaton, M.G., Sternberg, L., McFarlane, K. \& Sarda, A. (2016). Self-concealment in obsessive-compulsive disorder: Associations with symptom dimensions, help seeking attitudes, and treatment expectancy. Journal of Obsessive-Compulsive and Related Disorders, 11, 43-48.

World Health Organization (1992). The ICD-10 Classification of mental and behavioural disorders. Clinical descriptions and diagnostic guidelines (10th revision). Geneva: Author.

Wismeijer, A.A.J. (2011). Self-concealment and secrecy: Assessment and associations with subjective well-being. Saarbrücken: LAP LAMBERT Academic Publishing. 
Table 1. Main demographic characteristics. Frequencies and percentages of the sample $(\mathrm{N}=103)$.

\begin{tabular}{|c|c|c|c|}
\hline & & $\mathrm{F}$ & $\%$ \\
\hline \multirow[t]{2}{*}{ Sex } & Male & 60 & 58.3 \\
\hline & Female & 43 & 41.7 \\
\hline \multirow[t]{2}{*}{ Age } & Mean: 49.68 & & \\
\hline & SD.: 12.28 & & \\
\hline \multirow[t]{5}{*}{ Marital status } & Single & 65 & 63.1 \\
\hline & Married/with partner & 19 & 18.5 \\
\hline & Separated/divorced & 17 & 16.5 \\
\hline & Widow & 2 & 1.9 \\
\hline & Total & 103 & 100 \\
\hline \multirow[t]{6}{*}{ Living arrangements } & Alone & 28 & 27.2 \\
\hline & Family of origin & 58 & 56.3 \\
\hline & Shared flat & 2 & 1.9 \\
\hline & With partner & 12 & 11.7 \\
\hline & Residence/supervised flat & 3 & 2.9 \\
\hline & Total & 103 & 100 \\
\hline \multirow[t]{5}{*}{ Education } & No education & 7 & 6.8 \\
\hline & Primary & 32 & 31.1 \\
\hline & Secondary & 50 & 48.5 \\
\hline & University & 14 & 13.6 \\
\hline & Total & 103 & 100 \\
\hline Employment situation & Housework & 5 & 4.9 \\
\hline
\end{tabular}


Inactive (unemployed)

Active (employed)

Inactive (Employment

disability)

Inactive (Retired)

Other

Total
17

16.5

43

41.7

5.8

12

11.7

100 
Table 2. Main clinical characteristics of the sample.

F or M

or SD

\begin{tabular}{|c|c|c|c|}
\hline ICD-10 diagnosis & Paranoid schizophrenia (F20.0) & 65 & 63.1 \\
\hline & Undifferentiated schizophrenia (F20.3) & 2 & 1.9 \\
\hline & Residual schizophrenia (F20.5) & 3 & 2.9 \\
\hline & Simple-type schizophrenia (F20.6) & 4 & 3.9 \\
\hline & Schizophrenia, unspecified (F20.9) & 2 & 1.9 \\
\hline & Schizotypal disorder (F21) & 6 & 5.8 \\
\hline & Delusional disorder (F22) & 13 & 12.6 \\
\hline & Acute and transient psychotic disorders (F23) & 2 & 1.9 \\
\hline & Schizoaffective disorder (F25) & 5 & 4.9 \\
\hline & Other schizophrenia (F28) & 1 & 1 \\
\hline & Total & 103 & 100 \\
\hline Employment disability & No & 29 & 28.2 \\
\hline & Yes $33-49 \%$ & 30 & 29.1 \\
\hline & Yes $50-64 \%$ & 14 & 13.6 \\
\hline & Yes $65 \mathrm{o}>65 \%$ & 30 & 29.1 \\
\hline & Total & 103 & 100 \\
\hline Substance use & No & 49 & 47.6 \\
\hline & Yes & 40 & 38.8 \\
\hline & Fx-user & 14 & 136 \\
\hline
\end{tabular}




\begin{tabular}{|c|c|c|}
\hline $\begin{array}{l}\text { Age at onset of psychosis } \\
\text { (years) }\end{array}$ & 30.64 & 11.75 \\
\hline Diagnosis (years) & 19.04 & 10.88 \\
\hline $\begin{array}{l}\text { Pharmacological treatment } \\
\text { (years) }\end{array}$ & 17 & 10.43 \\
\hline Number of hospitalizations & 2.21 & 3.83 \\
\hline Acceptance (AAQ-II) & 26.12 & 11.23 \\
\hline Self-concealment ((SCS) & 32 & 12.96 \\
\hline $\begin{array}{l}\text { Social Functioning Scale } \\
\text { (SFS) }\end{array}$ & 98.62 & 11.07 \\
\hline $\begin{array}{l}\text { Clinical Global Impression } \\
(\mathrm{CGI}-\mathrm{SCH})\end{array}$ & 4.20 & 1.05 \\
\hline Insight (SUMD) & 2.77 & 1.16 \\
\hline $\begin{array}{l}\text { Awareness of effects of } \\
\text { medication (SUMD) }\end{array}$ & 2.70 & 1.12 \\
\hline $\begin{array}{l}\text { Awareness of social } \\
\text { consequences (SUMD) }\end{array}$ & 2.74 & 1.11 \\
\hline
\end{tabular}


Table 3. Bivariate relationships between clinical variables.

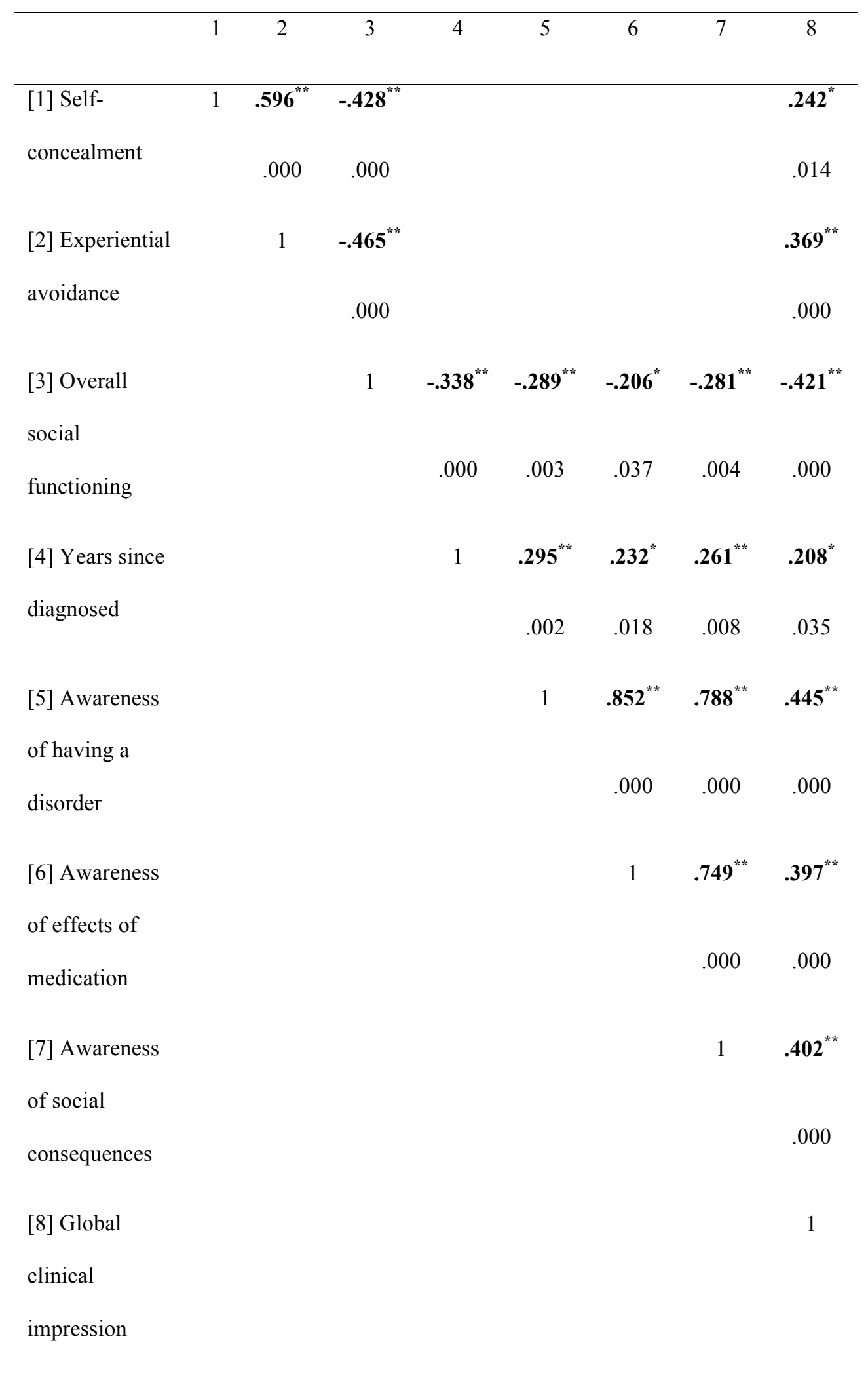

Note. ** Correlation is significant at 0.01 (two-tailed). ${ }^{*}$ Correlation is significant at 0.05 (two-tailed). Values of uncorrelated variables are not shown. 
Table 4. Predictor variables of social functioning.

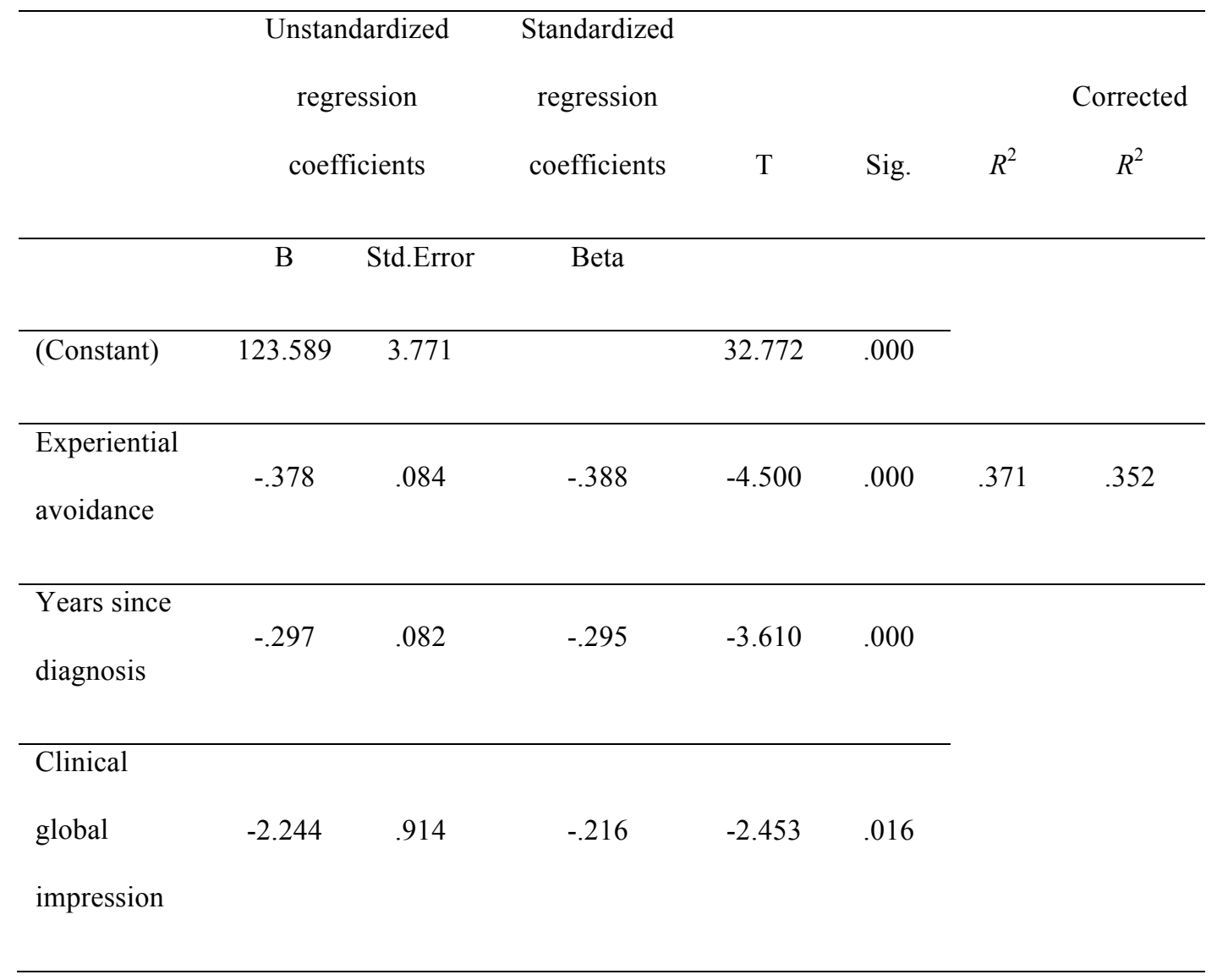

Note. Dependent variable: global score in SFS. 
Figure 1. Flow diagram for study participants.

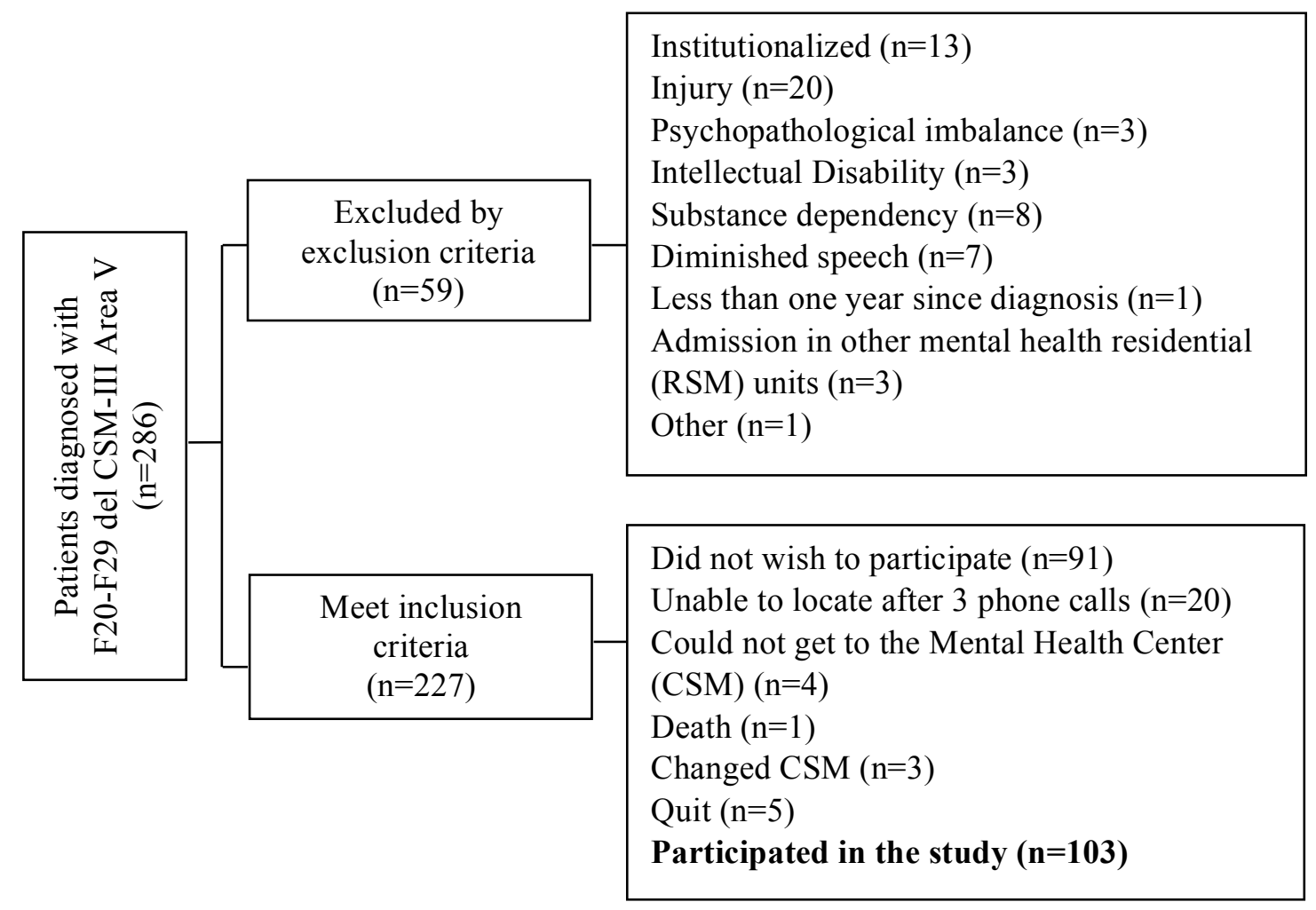

